\title{
The effect of changing grinding cycle on the flow-ability of cemented paste backfill: effect of particle size distribution
}

\author{
A Safarizadeh The University of Adelaide, Australia \\ A Taheri The University of Adelaide, Australia
}

\begin{abstract}
Cemented paste backfill (CPB) is an engineered design mixture that is commonly implemented to fill the left behind voids of mining. Depending on the sides of the stope under vertical and horizontal exposure, different mixture designs are needed to provide the minimum required strength to continue mining underfilled mass safely. Various parameters affect the strength of CPB and need to be checked daily as CPB quality control. One of the most important of these parameters is the particle size distribution (PSD). One way to increase the recovery of metal is to increase the milling time, which decreases the PSD of tailings significantly. This particle size reduction can undoubtedly change the properties of CPB. This study investigates the effect of changing $P S D$ on both the strength and flow-ability of CPB binary. In this regard, a range of tailings with variations of PSDs from 90\% less than $35 \mu \mathrm{m}$ to 90\% more than $35 \mu \mathrm{m}$ were prepared. P10 and P80 of samples were meticulously obtained and unconfined compressive strength (UCS), slump, and density tests conducted on $52 \mathrm{~mm}$ cylinder-shaped samples with a cylinder shape slump coin and with a Marcy scale. The results show that decreasing PSD can have a negative effect on the flow-ability of CPB, but strength first decreased; and then by a further decrease of PSD, strength increased significantly. Outcomes of this research were applied to CSA Mine's paste mixture due to the changes in the milling circle. Furthermore, the results of this research can be considered for backfill design if the PSD size has exceeded the limitations.
\end{abstract}

Keywords: paste, particle size distribution, tailings, flow-ability

\section{Introduction}

The last step of the mining sequence in most of the hard rock mining methods (excluding caving methods) is filling the stope, which allows secondary stopes to be mined. In the last few decades, the different filling methods implemented can be classified into two main groups, namely un-cemented filling methods like waste rock filling (WR or co-disposal) and cemented filling methods such as cemented waste rockfill (WRF), cemented hydraulic fill and cemented paste fill (CPB). The suitability of the fill type depends on how the other stopes are exposed to the primary stope. In recent years, CPB is mainly considered as a high production fill type that allows additional stopes to be mined faster (Belem \& Benzaazoua 2004; Kesimal et al. 2005; Bentz 2008; Helinski et al. 2011).

A wide range of new paste plants is constructed in two sections of paste plant and filter plant, which allow system runs with either directly coupled feed from the mill or reclaimed tailings from tailings storage facilities. By using direct-coupled feed for the mill, any changes in the grinding cycle and sequence in tailings particle size distribution (PSD) can significantly increase the risk of blockage or historically decrease the quality of paste, compromising the current levels of performance being achieved by the current PSD range (Deng et al. 2018). Supplementary to this matter, it is essential to arrive at the optimum solid content that will give satisfactory flow characteristics while maximising the tailing disposal.

In this regard, experimental activities were required to determine the optimal amount of binder and solids characteristics that can be used to achieve the recommended strengths for backfilling of the stopes as this is influenced by several factors that are difficult to predict. For this reason, two main parameters of paste flow-ability and strength were investigated in fixed solid content and fixed slump number condition, 
respectively. The effect on paste strength has been investigated before. However, this study explores the effect of PSD on the rheology and strength of CPB material.

\section{Experimental study}

\subsection{Material}

All the material was provided by CSA Mine in Australia as the mine aimed to generate new knowledge of the form of a practical PSD range and other physical modifications to formulate a novel paste backfill mix for this purpose.

\subsubsection{Binder}

Low heat cement with a ground granulated blast furnace slag constitute, commonly known as slag blended with general-purpose cement, was utilised as a binder in paste backfill mixture. Table 1 summarises the properties of the binder.

\section{Table 1 Binder properties}

\begin{tabular}{lll}
\hline Chemical entity & Proportion & Chemical abstracts service number \\
\hline Portland cement clinker & $20-95 \%$ & $65997-15-1$ \\
Ground granulated blast furnace slag & $70-80 \%$ & $65996-69-2$ \\
Fly ash (where applicable) & $8-50 \%$ & $68131-74-8$ \\
Gypsum $\left(\mathrm{CaSO}_{4} 2 \mathrm{H}_{2} \mathrm{O}\right)$ & $0-5 \%$ & $10101-41-4$ \\
Calcium oxide & $0-3 \%$ & $1305-78-8$ \\
Limestone $\left(\mathrm{CaCO}_{3}\right)$ & $0-5 \%$ & $1317-65-3$ \\
Hexavalent chromium $\mathrm{Cr}(\mathrm{VI})$ & $<20 \mathrm{ppm}$ & $1333-82-0$ \\
Crystalline silica (quartz) & $<1$ up to $10 \%$ & $14808-60-7$ \\
\hline
\end{tabular}

\subsubsection{Tailings and water}

The one-month-old tailings cake produced by the filter plant was used in the mixtures. It played a negative role as the tailings contained a high percentage of pyrite and by the time of testing, $\mathrm{pH}$ of tailings dropped sharply into the acidic zone. The properties of the tailings are summarised in Table 2.

Table 2 Elemental analysis of tailings composite

\begin{tabular}{lllllllll}
\hline Element & Unit & Average & Element & Unit & Average & Element & Unit & Average \\
\hline $\mathrm{B}$ & $\mathrm{ppm}$ & 10.00 & $\mathrm{Se}$ & $\mathrm{ppm}$ & 5.47 & $\mathrm{Ag}$ & $\mathrm{ppm}$ & 2.68 \\
$\mathrm{Ba}$ & $\mathrm{ppm}$ & 11.27 & $\mathrm{Sn}$ & $\mathrm{ppm}$ & 9.30 & $\mathrm{As}$ & $\mathrm{ppm}$ & 8.40 \\
$\mathrm{Bi}$ & $\mathrm{ppm}$ & 148.73 & $\mathrm{Te}$ & $\mathrm{ppm}$ & 0.08 & $\mathrm{Mn}$ & $\mathrm{ppm}$ & 1492.81 \\
$\mathrm{Cd}$ & $\mathrm{ppm}$ & 0.50 & $\mathrm{Al}_{2} \mathrm{O}_{3}$ & $\%$ & 9.35 & $\mathrm{TiO} 2$ & $\%$ & 0.32 \\
$\mathrm{Co}$ & $\mathrm{ppm}$ & 40.20 & $\mathrm{CaO}$ & $\%$ & 0.91 & $\mathrm{Fe}$ & $\mathrm{ppm}$ & 130387.67 \\
$\mathrm{Mo}$ & $\mathrm{ppm}$ & 1.00 & $\mathrm{SiO}_{2}$ & $\%$ & 62.02 & $\mathrm{MgO}$ & $\%$ & 2.99 \\
$\mathrm{Sb}$ & $\mathrm{ppm}$ & 1.52 & $\mathrm{Cu}$ & $\mathrm{ppm}$ & 1154.43 & $\mathrm{MnO}$ & $\%$ & 0.22 \\
$\mathrm{Be}$ & $\mathrm{ppm}$ & 0.36 & $\mathrm{~S}$ & $\%$ & 0.38 & $\mathrm{Si}$ & $\%$ & 28.99 \\
$\mathrm{Hg}$ & $\mathrm{ppm}$ & 0.04 & $\mathrm{~Pb}$ & $\mathrm{ppm}$ & 41.14 & $\mathrm{Cl}$ & $\%$ & 0.01 \\
$\mathrm{Ni}$ & $\mathrm{ppm}$ & 17.46 & $\mathrm{Zn}$ & $\mathrm{ppm}$ & 132.63 & $\mathrm{~F}$ & $\mathrm{ppm}$ & 268.58 \\
\hline
\end{tabular}

For water as the last part of the mixture, ore processing water with a $\mathrm{pH}$ of 8 was used. This water was extracted from the tailings stream at the filter plant and was the main source of water for the CPB mixes. 


\subsection{Sample preparation}

The sampling method was as follows. Five series of samples were prepared with different PSD in two batches. First, by using a sieve $38 \mu \mathrm{m}$, samples were separated into $<38 \mu \mathrm{m}$ and $>38 \mu \mathrm{m}$ fractions. Samples were then mixed again in different ratios of these two fractions and the new PSD analysed.

The sample properties have been summarised in Table 3.

\section{Table 3 Sample properties}

\begin{tabular}{lllll}
\hline Sample\# & \% @ -38microns & \% @ +38microns & Binder content (\%) & Density (SG) \\
\hline PSD1\&PSD11 & 10 & 90 & 10 & 1.8 \\
PSD2\&PSD12 & 25 & 75 & 10 & 1.8 \\
PSD3\&PSD13 & 50 & 50 & 10 & 1.9 \\
PSD4\&PSD14 & 75 & 25 & 10 & 1.9 \\
PSD5\&PSD15 & 90 & 10 & 10 & 1.9 \\
\hline
\end{tabular}

Tailings were batched into the various mixes, taking into account their moisture. CPB trials were conducted using a hand paint mixer and a $20 \mathrm{~L}$ bucket. First, bleed samples were used for the slump test and then cast into $200 \mathrm{~mL}$ volumetric cylinders, and bleed volume was determined visually. Finally, for determining the actual paste solids content, a sample of each mix was obtained to be dried out in an oven at $110^{\circ} \mathrm{C}$.

\section{Apparatus and experimental tests}

The following test methods were used on these samples.

\subsection{Non-standard cylinder coin slump test}

The solids in the mix design and the range of the slump number were limited by the ability of the underground paste reticulation and how much pumping pressure it can produce before any failure or blockage. Based on these limitations, the solid content of the first series of samples, PSD1 to PSD5, was targeted to be fixed on $70 \%$. For all these samples, this percentage was the most practical solid content for the CSA Mine. For the second trial, samples PSD11 to PSD15, the slump number was attempted to be fixed around $120 \mathrm{~mm}$ (Table 4).

Table 4 Samples properties

\begin{tabular}{|c|c|c|c|c|c|c|c|c|}
\hline Sample & $\begin{array}{l}\%<38 \\
\text { microns }\end{array}$ & $\begin{array}{l}\text { Binder } \\
\text { content (\%) }\end{array}$ & $\begin{array}{l}\text { Actual } \\
\text { slump (mm) }\end{array}$ & $\begin{array}{l}\text { Diameter of } \\
\text { slump coin }(\mathrm{mm})\end{array}$ & $\begin{array}{l}\text { Density } \\
\text { (SG) }\end{array}$ & $\begin{array}{l}\text { Mixture } \\
\text { pH }\end{array}$ & $\begin{array}{l}\text { Design solid } \\
\text { content (\%) }\end{array}$ & $\begin{array}{l}\text { Actual solid } \\
\text { content (\%) }\end{array}$ \\
\hline PSD1 & 10 & 10 & 170 & 100 & 1.8 & 8.13 & 70 & 70.2 \\
\hline PSD2 & 25 & 10 & 165 & 84 & 1.8 & 8.13 & 70 & 70.1 \\
\hline PSD3 & 50 & 10 & 150 & 60 & 1.9 & 8.13 & 70 & 70.5 \\
\hline PSD4 & 75 & 10 & 95 & A25 & 1.9 & 8.13 & 70 & 70.4 \\
\hline PSD5 & 90 & 10 & 55 & 18 & 1.9 & 8.13 & 70 & 70.4 \\
\hline PSD11 & 10 & 10 & 120 & - & - & 8.13 & - & 75.5 \\
\hline PSD12 & 25 & 10 & 120 & - & - & 8.13 & - & 77.2 \\
\hline PSD13 & 50 & 10 & 115 & - & - & 8.13 & - & 75.9 \\
\hline PSD14 & 75 & 10 & 115 & - & - & 8.13 & - & 71.5 \\
\hline PSD15 & 90 & 10 & 115 & - & - & 8.13 & - & 69.0 \\
\hline
\end{tabular}


Due to the time-consuming process of the tailing preparation, around $5 \mathrm{~kg}$ of each sample was prepared. Hence, only the cylinder shape slump cone was used to check the flow-ability of the CPB samples (Figure 1). To find the correlation of the slump numbers with standard and non-standard slump cones, a separate sample was prepared and tested with both cones and the slump number of $120 \mathrm{~mm}$ with the cylinder shape cone performed almost $220 \mathrm{~mm}$ slump number conducted with standard slump cone.

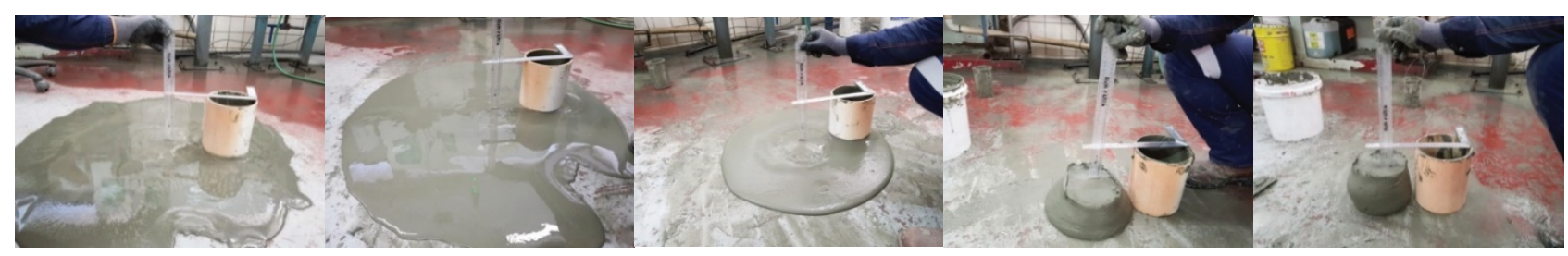

Figure 1 Changes in the slump number by changing the particle size: (a) PSD1; (b) PSD2; (c) PSD3; (d) PSD4; (e) PSD5

\subsection{Density test}

The density is a property dependent on the mass of tailings, mass of cement and mass of water added to a mix. The density of paste mixtures were measured utilising a Marcy scale for the samples of PSD11 to PSD15, as well as the samples of PSD1 to PSD5. For the samples PSD1 to PSD5, as they were prepared in a fixed solids content of $70 \%$, theoretically the densities were assumed to be same SG, but they were measured to identify any human error as well.

\subsection{Unconfined compressive strength test}

180 cylindrical samples were made from the mixtures and cured in the curing box. Three samples of each mixture were tested for uniaxial compressive strength at each curing times at 3,7 and 14 days. The remaining samples were tested after 28 and 56 days.

For the UCS tests, a VJ5011-RS Triplex $50 \mathrm{kN}$ compression machine with a stepper drive system provided strain rates from 0.01 to $50 \mathrm{~mm}$ per minute and a maximum stress load of $50 \mathrm{kN}$ implemented.

\subsection{Solid content test}

As a final check to verify the influence of the design and actual moisture variance, actual solid content of each sample was confirmed with the dry oven solid content test (Table 4).

\section{$4 \quad$ Results and discussion}

This section discusses the changes in CPB rheology in two sections of flow-ability in a constant solid content and strength change in a fixed slump number.

\subsection{Flow-ability: fixed solid content}

Density and slump tests are used for immediate action during CPB pouring to adjust the solid content and keep the mixture in the designed range. For each PSD, slump number and density using a Marcy scale were plotted against the corresponding PSD changes.

Figure 2 shows the slump number changing trend has an inverse relationship to the increasing PSD size for the samples PSD1 to PSD5 as fixed solid content of 70\%. The sample PSD1 performs the maximum flow-ability (minimum friction lost) but since the mass concentration and density in this case is the same, the flow-ability is influenced by the PSD. It should be noted that in practice, the slump is generally controlled by adding or removing water during the mixing process of the plant. 
This behaviour can be explained by the size of the tailings particle as there is a need for less water to saturate the surface of the coarse particle.

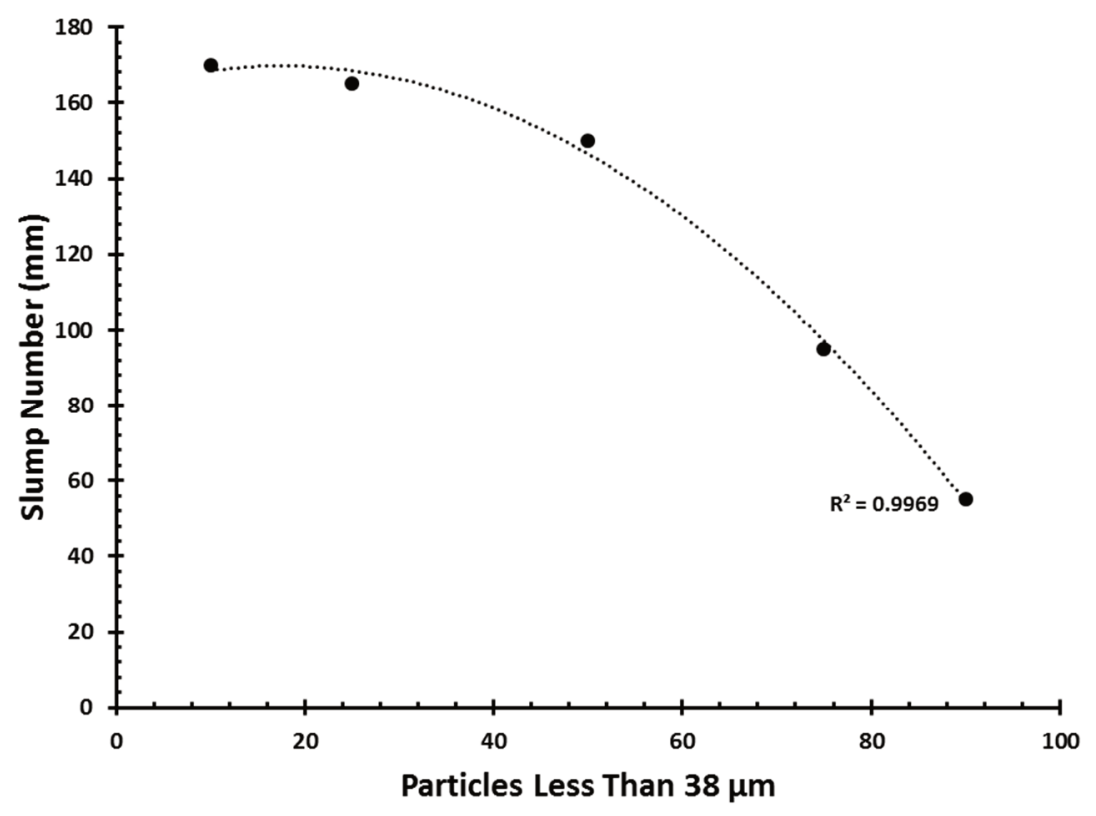

Figure 2 Slump number changes versus particle size distribution

As any slump number less than $110 \mathrm{~mm}$ was below the designed range for the underground reticulation, PSD5 performed a non-applicable mixture for the mine.

\subsection{Strength: fixed slump number}

In the second stage of this experiment, the strength of CPB is analysed based on the amount of the fine particle less than $38 \mu \mathrm{m}$. In the same slump number, PSD13 showed the highest strength and PSD15 showed the minimum strength. This was expected due to the high water/solid ratio in the PSD15 mix design. However, the PSD3 (the same PSD as PSD13) showed the lowest strength in the 70\% solid content.

Figure 3 shows the UCS results for the first test series of PSD1 to PSD5 and the second series of PSD11 to PSD15. 
Curing Time Vs. UCS for PSD1-PSD5 Samples

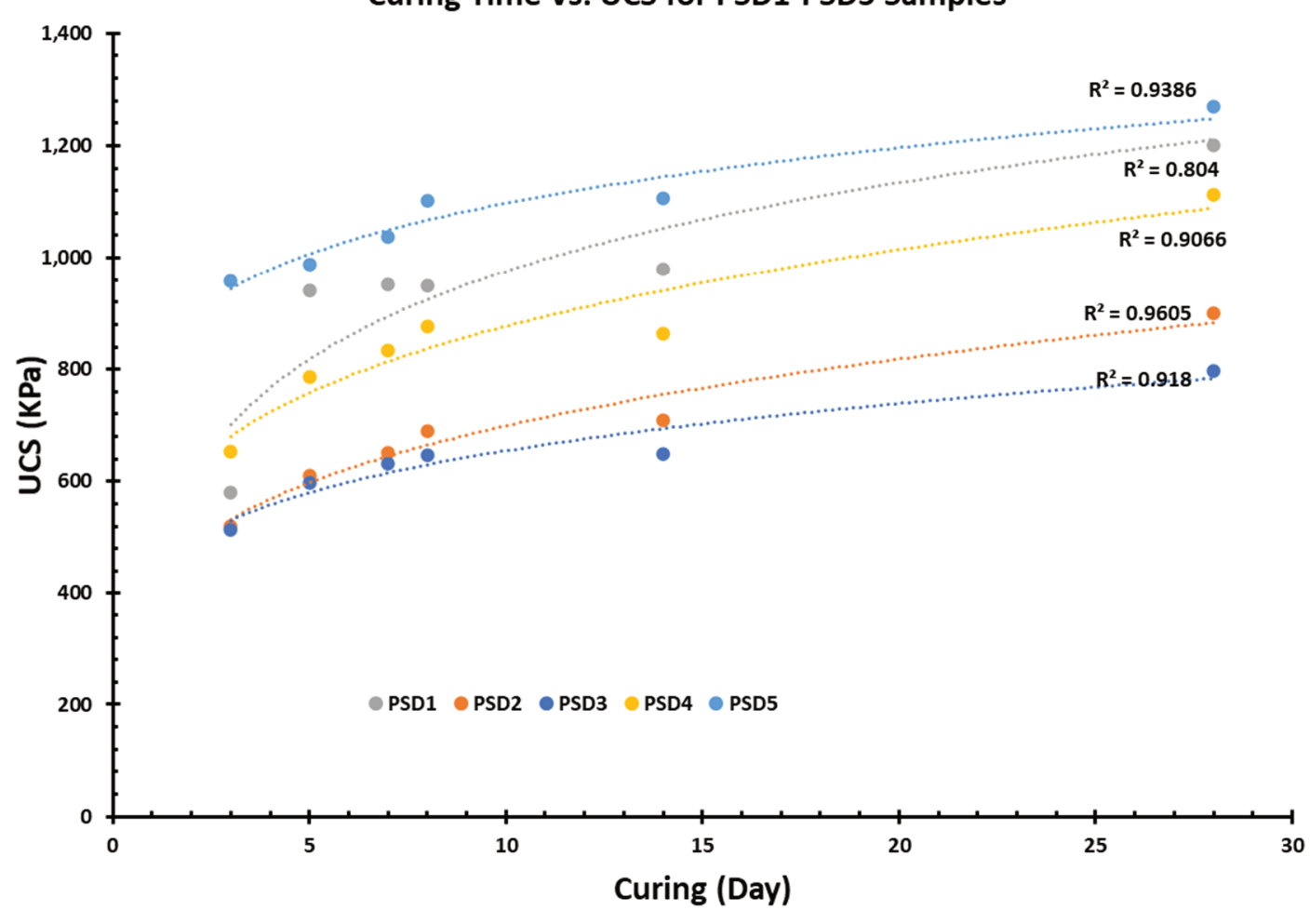

(a)

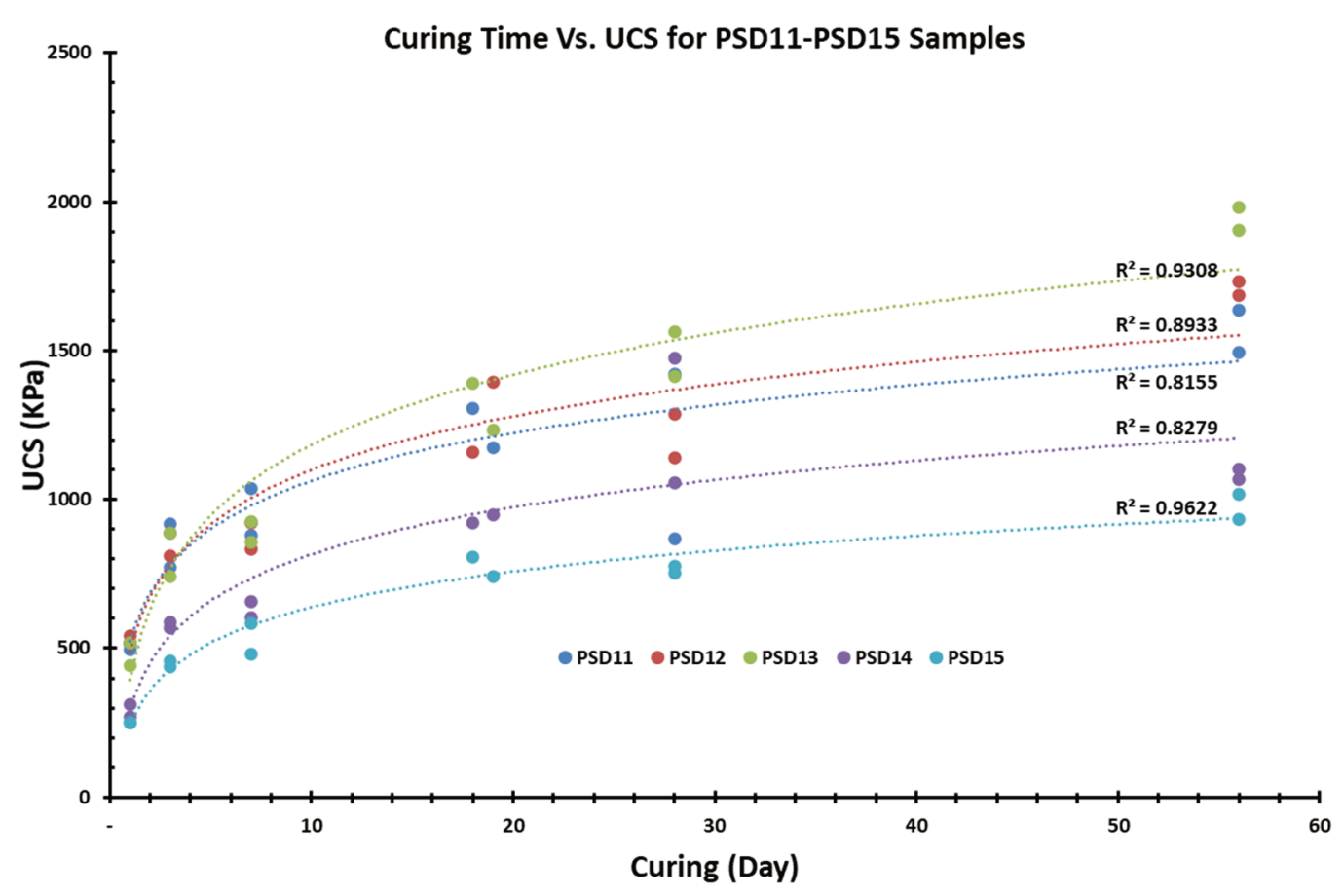

(b)

Figure 3 Comparing unconfined compressive strength (UCS) results of paste mixed in various particle size distributions in different curing time for: (a) Samples with the same solid content; (b) Samples with the same slump number 


\section{Conclusion}

The effect of changing PSD on the rheology of CPB was investigated with different mix designs and various size distribution of tailings. The results demonstrated the following:

- Both strength and flow-ability of CPB are required to be considered interdependent for any design. As general understanding, the solid content needs to be maximised in the mixture, but any system has its own limitation. It has been suggested to consider the maximum practical solid content as a critical parameter.

- In the first series of the mixes, PSD1-PSD5, the control with $10 \%$ binder and $70 \%$ solid content exhibited a significantly higher slump than what was originally anticipated with coarse tailings.

- Total flow-ability was increased when particle size was increased.

- For the samples with the same slump number, density was increased when particle size was decreased.

- With the same solid content, samples with $50 \%$ less than $38 \mu \mathrm{m}$ gained minimum strength.

- With the same slump number, samples with $50 \%$ less than $38 \mu \mathrm{m}$ gained maximum strength. It needs to take into account that the amount of water in this mix was more than PSD14 and PSD15 samples.

- With the same solid content, the sample with $90 \%$ less than $38 \mu \mathrm{m}$ gained maximum strength, but this sample was not practical.

- These results firmly indicated that more binder was required for the finer PSD to achieve the desired strength for CSA Mine. However, slump number less than $120 \mathrm{~mm}$ was non-practicable for this case study. The samples with $50 \%$ less than $38 \mu \mathrm{m}$ was suggested as the optimum mix design.

\section{Acknowledgement}

The CSA Mine ostensibly supports this work under a business improvement project, and it is a pleasure for the authors to acknowledge help and support from Glencore-CSA Mine during the onsite testing and for providing the material and equipment.

The authors also acknowledge support from Jan Jacob and CSA lab technicians.

\section{References}

Bentz, DP 2008, 'A review of early-age properties of cement-based materials', Cement and Concrete Research, vol. 38, pp. $196-204$.

Belem, T \& Benzaazoua, M 2004, 'An overview on the use of paste backfill technology as a ground support method in cut-and-fill mines', in E Villaescusa \& Y Potvin (eds), Ground Support 2004: Proceedings of the Fifth International Symposium on Ground Support, Taylor \& Francis Group, London, pp. 637-650.

Deng, XJ, Klein, B, Hallbom, DJ, de Wit, B \& Zhang, JX 2018, 'Influence of particle size on the basic and time-dependent rheological behaviour of cemented paste backfill', Journal of Materials Engineering and Performance, vol. 27, pp. 3478-3487.

Helinski, M, Fahey, M \& Fourie, A 2011, 'Behaviour of cemented paste backfill in two mine stopes: measurements and modelling', Journal of Geotechnical and Geoenvironmental Engineering, vol. 137, issue 2, pp. 171-182.

Kesimal, A, Yilmaz, E, Ercikdi, B, Alp, I \& Deveci, H 2005, 'Effect of properties of tailings and binder on the short-and long-term strength and stability of cemented paste backfill', Materials Letters, vol. 59, pp. 3703-3709. 
